\title{
Synthesis of flexible dimeric meso-tetrakis-porphyrins
}

\author{
Abilio J. F. N. Sobral, ${ }^{a}, *$ Susana M. Melo, ${ }^{a}$ M. Luísa Ramos, ${ }^{a}$ Raquel Teixeira, ${ }^{b}$ \\ Susana M. Andrade ${ }^{\mathrm{b}}$ and Silvia M. B. Costa ${ }^{\mathrm{b}, *}$ \\ ${ }^{a}$ Departamento de Química, Universidade de Coimbra, Rua Larga, 3004-535 Coimbra, Portugal \\ ${ }^{\mathrm{b}}$ Centro de Química Estrutural, Instituto Superior Técnico, UTL, 1049-001 Lisboa, Portugal
}

Received 12 February 2007; revised 5 March 2007; accepted 7 March 2007

Available online 12 March 2007

\begin{abstract}
Monofunctionalisation of meso-tetrakis-porphyrins through introduction of a carboxylic group in the meso position of the phenyl group confers the necessary characteristics to anchor them through stable amide bonds to functionalised supports or to molecules. In this Letter we describe the synthesis, characterisation and photophysical evaluation of such a functionalised flexible dimeric porphyrin, bis-(meso-tetrakis-5,10,15-triphenyl-20-(p-carboxyphenyl)-porphyrinyl)-1,6-hexanediamide.
\end{abstract}

(C) 2007 Elsevier Ltd. All rights reserved.

The unique photophysical and photochemical properties of porphyrins and related macrocycles make them an extremely versatile class of compounds for a variety of applications in medicine, catalysis, conversion of solar energy and nanotechnology. ${ }^{1-7}$

Dimeric porphyrin arrays (bis-porphyrins) in particular are important for supramolecular recognition and energy or electron donor-acceptor systems. The bisporphyrins are the simplest elements in porphyrin based nanostructures and consequently several methods have been developed to achieve efficient and controlled synthesis of porphyrin-spacer-porphyrin systems. Since the nature of the linker has a strong influence on the overall properties of the porphyrin dimers, affecting both physical (solubility, aggregation behaviour or photo response) and chemical properties (reactivity or thermal stability) a large amount of work has been done over the last four decades on the synthesis and evaluation of the physical properties of a number of bis-porphyrins. The actual bis-porphyrin based design of porphyrin-spacer-porphyrin systems, with organic ionic, metal ionic or organic covalent linked spacers constitutes a diverse set of molecular types, involving mesofree porphyrins, meso-tetrakis-porphyrins and a combination of both, with spacers ranging from a few atoms to complex spacers of lengths extending to dozens of

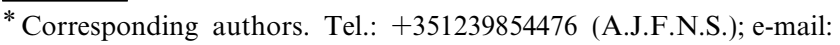
asobral@ci.uc.pt
}

angstroms, having saturated molecules, aromatics or other highly conjugated motifs as spacers. ${ }^{8-13}$

In spite of this intense activity, synthesis of new bis-porphyrins is still an area of high potential, both in terms of improving low yields generally obtained in the synthetic process as well as discovering novel properties from new assemblies of porphyrins and spacers, as in the case of the long saturated spacers between meso-phenyl-porphyrins. Since most of the work has been done with conjugated spacers to favour the electronic interaction among the two porphyrins, mostly with restricted rotation, there is a lack in the evaluation of the interaction of two porphyrins restricted in the same volume but without direct conjugation between their electronic systems. This has led us to plan and synthesise the title compound, whose photophysical properties are also presented.

Optical absorption spectra of porphyrins were recorded on a Jasco V-560 UV-vis absorption spectrophotometer. Fluorescence measurements were made on a Perkin-Elmer LS50B spectrofluorometer. The instrumental response at each wavelength was corrected by means of a curve obtained using appropriate fluorescence standards. The sample holders of both instruments were thermostated at $25.0^{\circ} \mathrm{C}$ and all measurements were performed with [Porphyrin] $\sim 4 \mu \mathrm{M}$ in acetonitrile using $10 \mathrm{~mm}$ path length quartz cells. MM2 calculations were performed in a Pentium 4 workstation at $3.2 \mathrm{GHz}$, via CambridgeSoft Chem3D Pro 7, 2001, USA, using a conjugated gradient algorithm for 
energy minimisation in vacuum, with a final gradient of $0.05 \mathrm{kcal} /(\AA \mathrm{mol})$.

We isolated the mono functionalised porphyrin (1) in a $5 \%$ yield from the statistical mixture of porphyrins resulting from the cross condensation of benzaldehyde and 4-carboxy-benzaldehyde with $1 H$-pyrrole, in aerated propionic acid and acetic anhydride solution at $130^{\circ} \mathrm{C}$. After conversion of the carboxyl group to its acyl chloride by $\mathrm{SOCl}_{2}$, the porphyrin was coupled with hexane-1,6-diamine to give dimeric porphyrin (2) (H4DTPP) or with $n$-butylamine to give porphyrin (3) (TPP-CONHBu1), as shown in Scheme 1. All compounds gave the expected spectroscopic and analytical data for the suggested structures.

The electronic absorption spectra were examined in acetonitrile and compared with that of TPP-CONHBul under similar conditions. Figure 1 shows the absorption spectra of $\mathrm{H}_{4}$ DTPP (in bold) and of TPP-CONHBu1.
These display common features, with both exhibiting a single Soret (B) and four Q-bands. The similar spectra and lack of splitting of the bands indicate that no distortions occur in ring planarity. The lack of splitting of the Soret band suggests that the electronic states of the dimer are not perturbed compared with that of the monomeric porphyrins.

According to exciton coupling theory, the transition dipole moments for each moiety interact electrostatically to create two exciton states, $\Psi^{\mid}$and $\Psi^{-}$. The $\Psi^{\mid}$state corresponds to the case where both monomeric units are excited in phase, while for the $\Psi^{-}$state, both monomers are out of phase. The absorption energies of the transitions depend on the angle between the transition dipoles and the relative phase of their excitations. The exciton is expected to be strong in directly meso-linked arrays because of the short interconnection between porphyrin moieties. However, in the present case the interconnection between units is large enough to allow
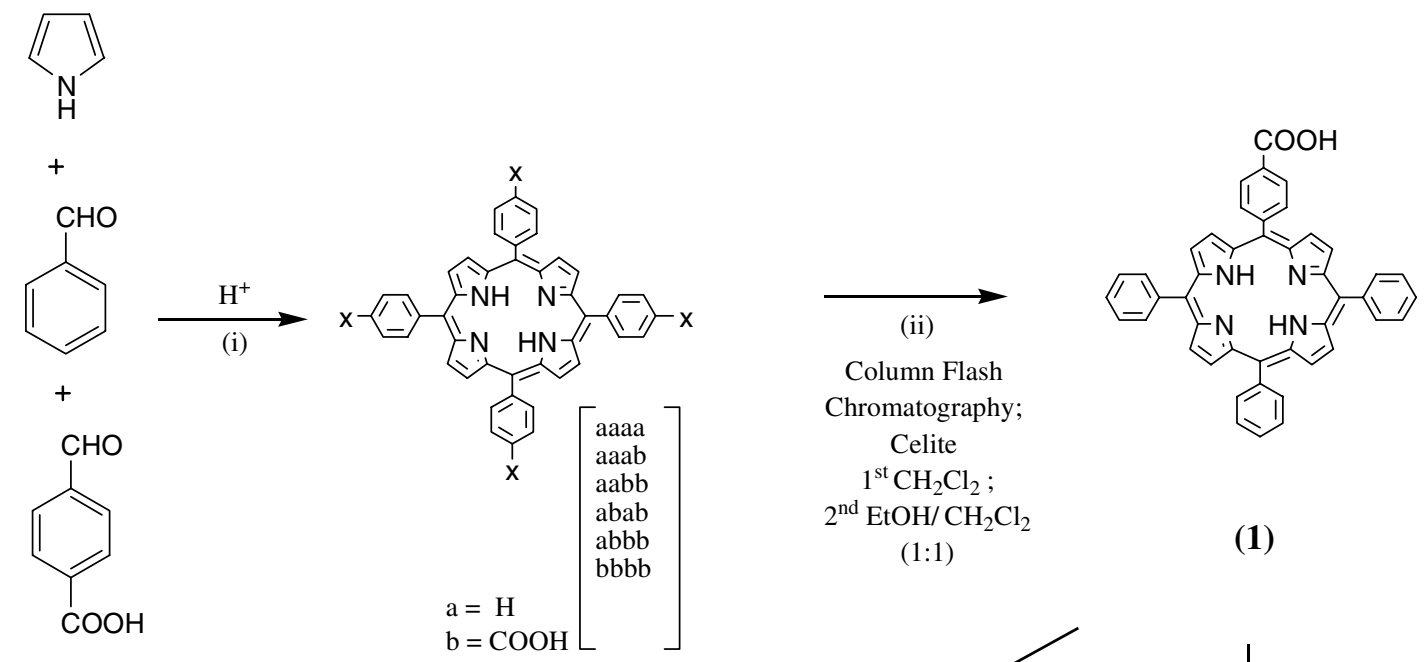

$1^{\text {st }} \mathrm{CH}_{2} \mathrm{Cl}_{2}$; $2^{\text {nd }} \mathrm{EtOH} / \mathrm{CH}_{2} \mathrm{Cl}_{2}$ $(1: 1)$

(1)
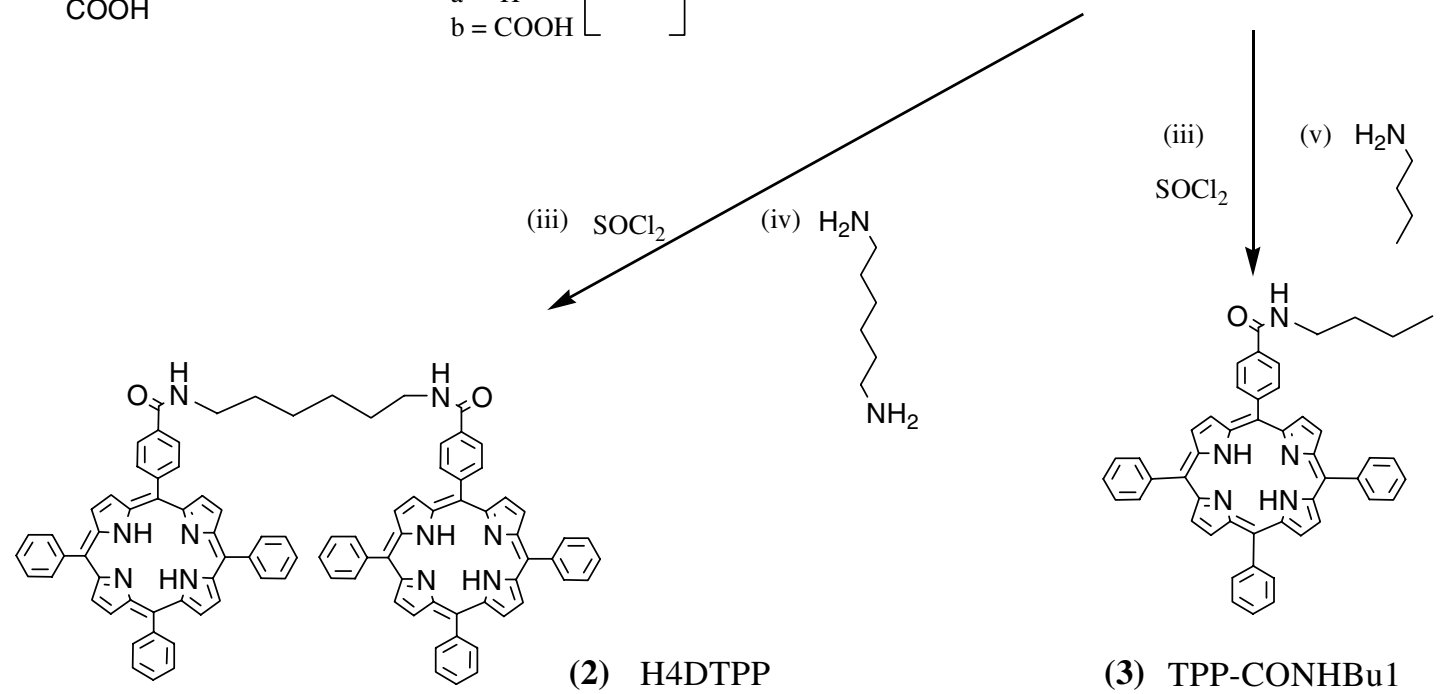

(3) TPP-CONHBu 1

Scheme 1. Reagents and conditions: (i) Propionic acid, acetic anhydride, benzaldehyde, 4-carboxy-benzaldehyde, 1H-pyrrole; (1)/(2)/(3)

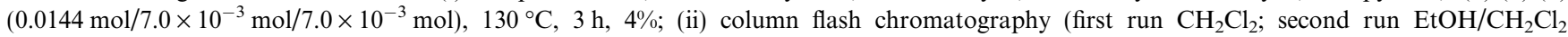
(1:1)); (iii) $\mathrm{K}_{2} \mathrm{CO}_{3}$ anhydrous, $\mathrm{CH}_{2} \mathrm{Cl}_{2}, 32{ }^{\circ} \mathrm{C}, \mathrm{SOCl}_{2}, 6 \mathrm{~h}$; (iv) hexane-1,6-diamine, $32{ }^{\circ} \mathrm{C}, 2 \mathrm{~h}, 10 \%$; (v) 1-butylamine, $32{ }^{\circ} \mathrm{C}, 1 \mathrm{~h}, 5 \%$. (1) $\mathrm{m} / z(\mathrm{FAB}$ MS, NBA) $659.9\left(100 \%,[\mathrm{M}+\mathrm{H}]^{+}, \mathrm{C}_{45} \mathrm{H}_{30} \mathrm{~N}_{4} \mathrm{O}_{2}\right.$ requires 658.7$),{ }^{1} \mathrm{H}$ NMR $500 \mathrm{MHz}\left(0.01 \mathrm{M}\right.$ in $\left.\mathrm{CDCl}_{3}\right): \delta 11.1(\mathrm{br} \mathrm{s}, 1 \mathrm{H}, \mathrm{COOH}), \delta 8.88(\mathrm{~m}, 6 \mathrm{H}$, $\left.\beta \mathrm{H}_{\mathrm{a}}\right), \delta 8.83\left(\mathrm{~m}, 2 \mathrm{H}, \beta \mathrm{H}_{\mathrm{b}}\right), 8.51\left(\mathrm{dd}, J 2.8 \mathrm{~Hz}, 2 \mathrm{H}, \mathrm{Subst} . \mathrm{ArH}_{o}\right), 8.36\left(\mathrm{dd}, J 2.8 \mathrm{~Hz}, 2 \mathrm{H}, \mathrm{Subst} . \mathrm{ArH}_{m}\right), \delta 8.24\left(\mathrm{~m}, 6 \mathrm{H}, \mathrm{ArH}_{m}\right) \delta 7.80\left(\mathrm{~m}, 9 \mathrm{H}, \mathrm{ArH}_{o, p}\right)$, $\delta-2.51(\mathrm{~m}, 2 \mathrm{H}, \mathrm{NH})$. Inset: (a) MALDI-TOF mass spectra for (2), DHB matrix with calibration mixture Pepmix $1, \mathrm{M}^{+\cdot}$ at $\mathrm{m} / z 1396.96$ $\left(\mathrm{C}_{96} \mathrm{H}_{72} \mathrm{~N}_{10} \mathrm{O}_{2}\right.$ requires 1396.58) and (b) ESI MS for (3) $\mathrm{m} / z(\mathrm{FAB}, \mathrm{NBA})[\mathrm{M}+\mathrm{H}]^{+}$at $714.6\left(\mathrm{C}_{49} \mathrm{H}_{39} \mathrm{~N}_{5} \mathrm{O}\right.$ requires 713.4$)$. 

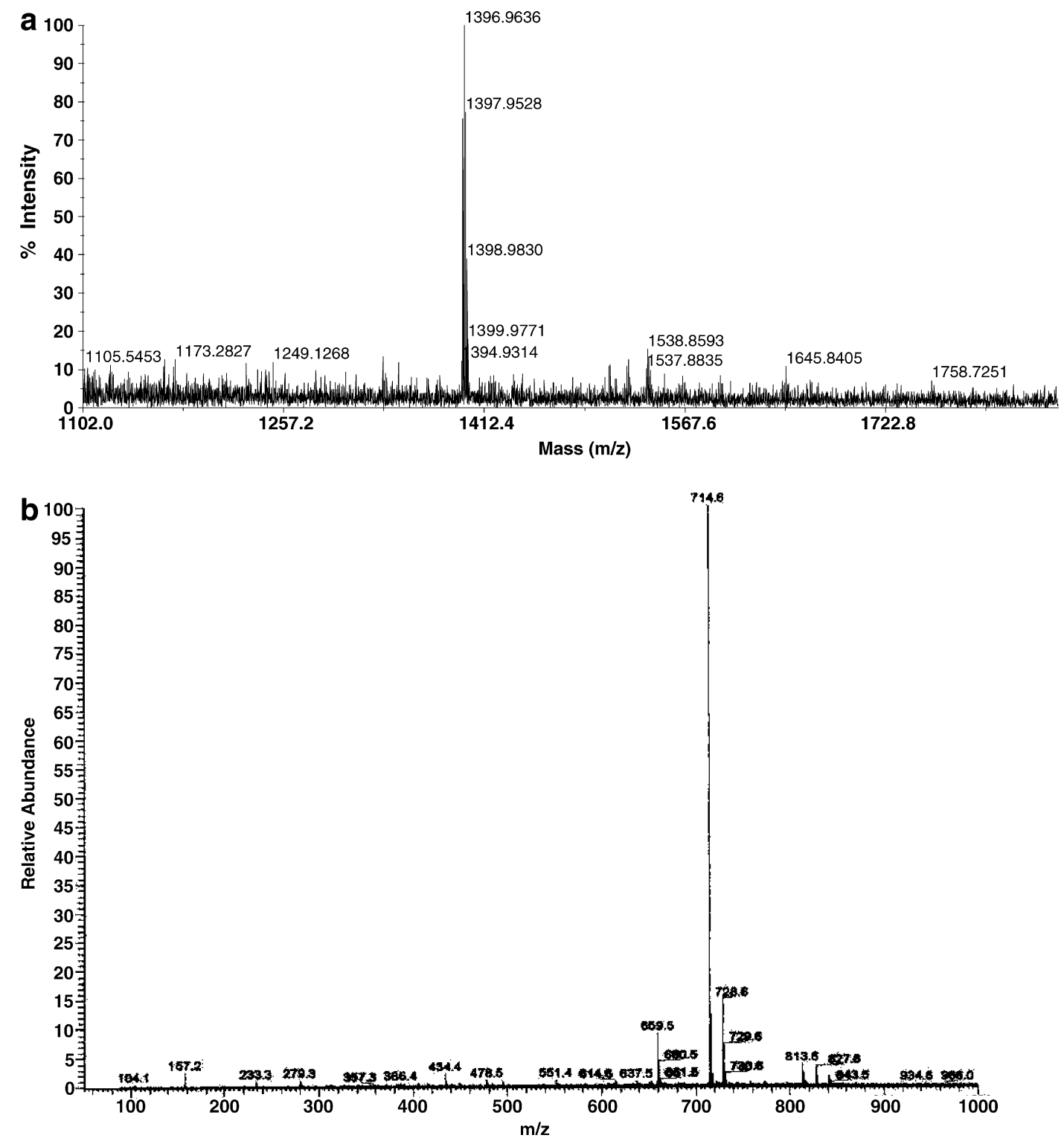

Scheme 1 (continued)

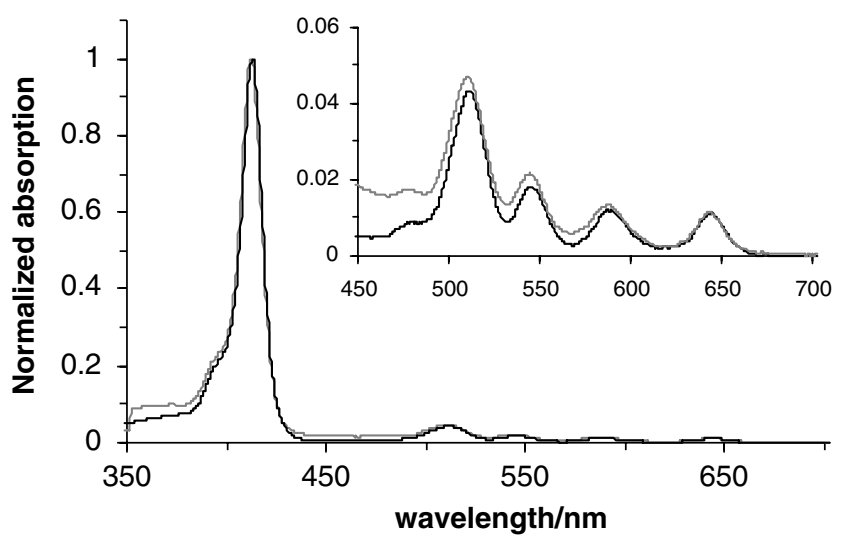

Figure 1. Normalised UV-vis absorption spectra of $\mathrm{H}_{4} \mathrm{DTPP}$ (black line) and TPP-CONHBul (grey line) in acetonitrile. Inset: Expanded absorption spectra in Q-band region.

for a considerable angular distribution, such that exciton coupling is weak (or nonexistent). The perturbations sensed in the Q-band region are even less marked due to the much smaller transition dipole moments compared with those of B-bands.

The fluorescence emission spectrum of TPP-CONHBu1 in acetonitrile exhibits two vibronic emission bands centred at 650.5 and $717.5 \mathrm{~nm}$ (see Table 1) independent of the excitation wavelength, Figure 2. In the case of $\mathrm{H}_{4}$ DTPP, however, besides two similar vibronics, a totally new band is detected at higher energies (centred at $543 \mathrm{~nm}$ ) with an intensity (INT) that, in contrast to the two longer wavelength emissions, depends on the excitation wavelength, with $\operatorname{INT}\left(\lambda_{\mathrm{exc}}=375 \mathrm{~nm}\right)>$ $\operatorname{INT}\left(\lambda_{\mathrm{exc}}=508 \mathrm{~nm}\right)>\operatorname{INT}\left(\lambda_{\mathrm{exc}}=420 \mathrm{~nm}\right)$.

The excitation spectra also show a dependence on the emission wavelength. The spectrum obtained collecting emission at the usual vibronic bands (650 or $712 \mathrm{~nm}$ ) is clearly superimposable on the absorption spectrum, both in Soret and Q-band regions. However, when the 
Table 1. Comparison of photophysical parameters of $\mathrm{H}_{4} \mathrm{DTPP}$ and TPP-CONHBul in acetonitrile

\begin{tabular}{|c|c|c|c|c|c|c|c|c|c|}
\hline \multirow[b]{3}{*}{$\mathrm{H}_{4} \mathrm{DTPP}$} & \multicolumn{5}{|c|}{ Absorption maxima (nm) } & \multicolumn{3}{|c|}{ Emission maxima (nm) } & \multirow[t]{2}{*}{$\phi_{\mathrm{f}}{ }^{\mathrm{a}}$} \\
\hline & $\mathrm{B}$ (Soret) & $\mathrm{Qy}(1,0)$ & $\mathrm{Qy}(0,0)$ & $\mathrm{Qx}(1,0)$ & $\overline{Q x(1,0)}$ & & & & \\
\hline & $413.5(2.54)^{\mathrm{b}}$ & 512.0 & 546.0 & 589.0 & 644.0 & 542.0 & 650.0 & 716.0 & 0.12 \\
\hline TPP-CONHBu1 & $413.0(2.02)^{\mathrm{b}}$ & 512.5 & 545.5 & 588.0 & 643.0 & - & 650.5 & 717.5 & 0.10 \\
\hline
\end{tabular}

${ }^{\mathrm{a}} \lambda_{\mathrm{exc}}=508 \mathrm{~nm}$ using for reference TPP in benzene with $\phi_{\mathrm{f}}=0.11$.

${ }^{\mathrm{b}}$ Molar extinction coefficient, $\varepsilon / 10^{5} \mathrm{M}^{-1} \mathrm{~cm}^{-1}$.
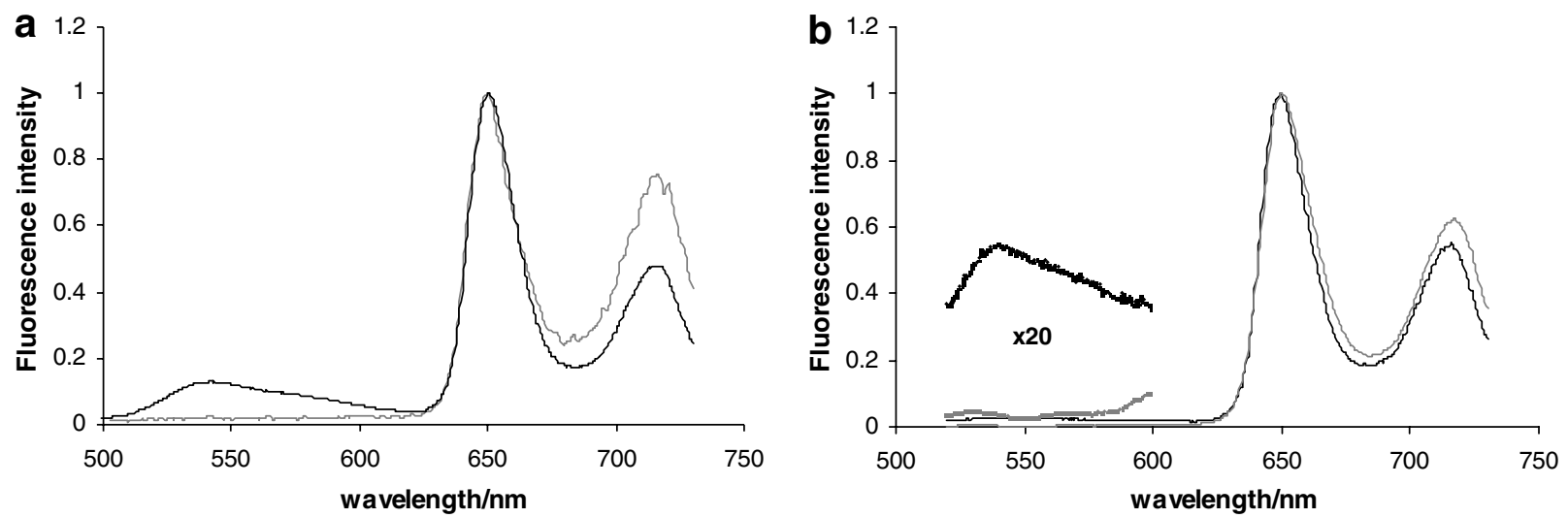

Figure 2. Normalised fluorescence spectra of $\mathrm{H}_{4} \mathrm{DTPP}$ (black line) and of TPP-CONHBul (grey line) in acetonitrile obtained upon excitation at (a) $375 \mathrm{~nm}$ and at (b) $508 \mathrm{~nm}$ (inset: amplification of fluorescence intensity in the high energy region).

emission is observed at shorter wavelengths (e.g., $610 \mathrm{~nm}$ and $540 \mathrm{~nm}$, in Fig. 3) a new band is detected in the corresponding excitation spectra with a maximum at $375 \mathrm{~nm}$. In contrast, the intensity of the band com-

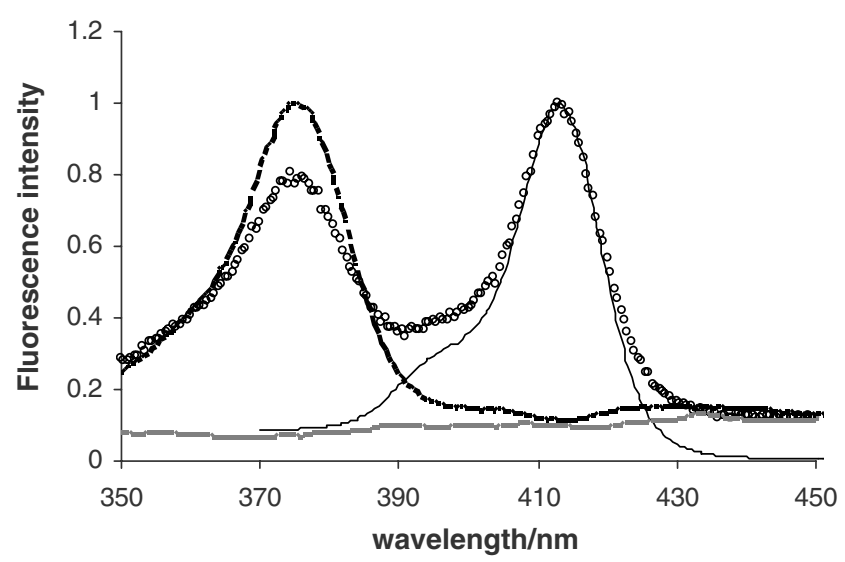

Figure 3. Normalised excitation spectra of $\mathrm{H}_{4} \mathrm{DTPP}$ in acetonitrile collected at different emission wavelengths: $712 \mathrm{~nm}$ (black thin line); $610 \mathrm{~nm}(\circ \circ)$ ); $540 \mathrm{~nm}(---)$ and (grey bold line for TPP-CONHBu1). mon to absorption (centred at $413 \mathrm{~nm}$ ) decreases, and it is not detectable when emission is collected near the new emission band maximum $(540 \mathrm{~nm})$. It is possible that upon excitation, a different configuration of the two porphyrin moieties is achieved, probably facilitated by the polar aliphatic solvents.

This broad band at higher energies than the monomer emission appears in many aprotic and protic polar aliphatic solvents and decreases with the temperature, but is absent in the aromatic apolar toluene. Work is in progress in order to clarify these features in the fluorescence emission.

Preliminary molecular mechanic calculations in vacuum of the open and closed forms (Scheme 2) show that the 'closed form' is $26 \mathrm{kcal} / \mathrm{mol}$ more stable than the 'open form', due to favourable $\pi \cdots \pi$ stacking interactions. Although this calculated vacuum value is too high to correspond to solution conditions, and would dramatically favour the stability of closed form, in contrast to what is observed, this suggests a favourable interaction between the linked macrocycles, which will be diminished by the solvent molecules and could even be totally a

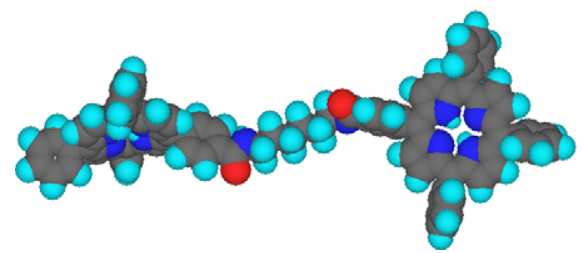

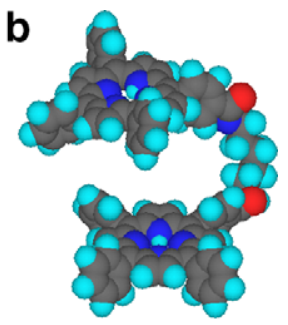

Scheme 2. Minimised conformational structures from molecular mechanical calculations (MM2) (a) 'open form' and (b) 'closed form'. 
quenched by aromatic molecules that would create competing $\pi \cdots \pi$ interactions with the macrocycles. This is in line with the observed photophysical behaviour.

\section{Acknowledgements}

Financial support from FCT (POCI/QUI/57387/2004), and $3^{\circ}$ Quadro Comunitário de Apoio is gratefully acknowledged. S.M.A. thanks FCT for a BPD Grant SFRH/BPD/24367/2005.

\section{References and notes}

1. Smith, K. M. J. Porphyrins Phthalocyanines 2000, 4, 319.

2. MacDonald, I. J.; Dougherty, T. J. J. Porphyrins Phthalocyanines 2001, 5, 105.

3. Fuchs, J.; Weber, S.; Kaufmann, R. Free Radic. Biol. Med. 2000, $28,537$.
4. Nyman, E. S.; Hynninen, P. H. J. Photochem. Photobiol. B 2004, 73, 1.

5. Dixon, D. W.; Gill, A. F.; Giribabu, L.; Vzorov, A. N.; Alam, A. B.; Compans, R. W. J. Inorg. Biochem. 2005, 99, 813.

6. Suslick, K. S.; Bhyrappa, P.; Chou, J.-H.; Kosal, M. E.; Nakagaki, S.; Smithenry, D. W.; Wilson, S. R. Acc. Chem. Res. 2005, 38, 283.

7. Rakow, N. A.; Sen, A.; Janzen, M. C.; Ponder, J. B.; Suslick, K. S. Angew. Chem., Int. Ed. 2005, 44, 4528.

8. Senge, M. O.; Reobler, B.; Gersdorff, J.; Scheafer, A.; Kurreck, H. Tetrahedron Lett. 2004, 45, 3363.

9. Punidha, S.; Ravikanth, M. Tetrahedron 2004, 60, 8437.

10. Gosper, J. J.; Ali, M. J. Chem. Soc., Chem. Commun. 1994, 1707.

11. Burrell, A. K.; Campbell, W.; Officer, D. L. Tetrahedron Lett. 1997, 38, 1249.

12. Genady, A. R.; Gabel, D. Tetrahedron Lett. 2003, 44, 2915.

13. Richeter, S.; Jeandon, C.; Ruppert, R.; Callot, H. J. J. Chem. Soc., Chem. Commun. 2001, 91. 